\title{
Impact and Visibility: What Place Does Psychology Occupy in the Brazilian and International Scientific Production?
}

We have closed off yet another year involved in the countless tasks that are part of the editorial process of a scientific journals committed to continuing improvement. Free access to qualified scientific knowledge is guaranteed. The manuscripts are fully published in English, so as to guarantee the journal's international insertion. In this new year, we will keep up our strong investments in the indexation of Paidéia in Brazilian and international databases. After all, the visibility of a scientific journal is guaranteed by its insertion in the main database indexing. We reassert our commitment to maintain free access to the full texts in English, as well as the submission process of original manuscripts and their assessment through peer review. As a counterpart, the authors are expected to bear the costs of translating their text to English.

Through these measures, we hope to continue attracting the best scientific contributions, which will reflect in a quality increase as a whole and in a higher impact factor. We know that the policy adopted by CAPES, the agency of the Brazilian Ministry of Education that assesses graduate programs in the country, has stimulated the rise in the impact factors of the journals the social actors of the graduate system publish their research results in. Nevertheless, recently, the bitter setbacks some Brazilian journals have gone through have shown that caution is due, maintaining one's serenity in response to the pressure suffered to insert our journals in the international context.

2013 witnessed fierce discussions about ethics in the editorial management of scientific journals, in Brazil as well as internationally. We witnessed the public debate about the strategies some journals adopt to further their impact factors, such as the unacceptable use of cross-references. Amidst the unavoidable scars, some crucial lessons could be learned from this sorry episode, which was widely disseminated in the media. The main lesson is that, in the rush to enhance the profile of the Brazilian journals, we cannot turn to spurious measures in order to artificially increase the impact factors of our journals.

We believe that this debate has strengthened the ethical premises that should guide scientific knowledge dissemination. The principle was reaffirmed that authentic and continuous efforts in the search to improve the editorial standards are more worthy. As we know, this upgrade work is gradual, slow and cumulate. It demands patience and, mainly, humility to acknowledge our limits. That is the only way we will be able to cope with our countless scientific development difficulties, as part of the countries newly admitted to the list of developing countries. And we will enhance our potential, always in accordance with our possibilities and with due serenity.
In 2011, a study was published by the researcher Marco Antonio Zago, former vice-dean of Research at the University of São Paulo, aimed at investigating what Brazilian studies are able to achieve large-scale international visibility (Zago, 2011). This study was published in the book Inovações tecnológicas no Brasil: Desempenho, politicas e potencial. The list of Brazilian articles that gained more than 200 citations and were published in the database of Thomson Reuters between 2001 and 2005 was surveyed. This benchmark discloses the prestige of the article, as it indicates that each paper was cited as a reference in at least 200 articles published in subsequent years. The list joins 123 articles, but the survey was further elaborated to filter those publications that could truly be considered an original contribution of Brazilian research in that period. This refinement revealed a set of 26 papers, subdivided among the areas of medicine (seven papers), chemistry (five), genomics (two), computer science (two), biochemistry (two), engineering (one) and ecology (one).

According to Marques (2011), the impact of an article is influenced by the originality of its contribution. The singular contribution of a study can be measured in terms of new findings added or the original interpretation of existing data, like in the case of reviews. In the select group of original Brazilian scientific publications compiled in that survey, none of the articles from Psychology and related areas was included. This clearly does not mean that the themes investigated by Brazilian psychological science had no international repercussions, or did not address themes of growing interest, or did not offer a new look on a given issue. We simply need to critically assess our place when we try to establish our profile alongside the other knowledge areas.

Zago (2011) alerts to certain limitations in the compilation. It is natural for medical articles to represent a majority among the frequently cited publications, as the area is particularly productive. And the number of citations is influenced by the size and productivity of the scientific community involved (Marques, 2011). The repercussion of the academic production varies from area to area. In areas with a more limited academic production, a paper is considered of extraordinary repercussions when it receives 50 or 100 citations. The repercussion of Brazilian studies in the social sciences and humanities is restricted. Some critics consider that this is due to two factors: the fact that they address themes of local interest and are mostly published in Portuguese.

According to the scientific director of the São Paulo Research Foundation (FAPESP), Carlos Henrique de Brito Cruz, the Brazilian scientific production has significantly increased in recent years, but the impact of the papers published 
remains below the global average, behind countries like Argentina, Spain, China and South Korea (Toledo, 2014). This reveals the dimension of the challenge the country is facing to achieve excellence in research. But the preponderant factor for our low visibility in this context is the difficulty we face to overcome the barriers and defeat the prejudices of international researchers with regard to the papers published in journals beyond the hegemonic axis of global scientific production.

We are convinced that conquering a place in the sun on the international Psychology scene involves the efforts of different generations and the perpetual commitment to the targets set through a coordinated action plan established by each journal's Editorial Board. Much remains to be done in the editorial management of Brazilian Psychology journal, in terms of editorial quality, dissemination, standardization, review process and acknowledgement of authorship, discussing the strengths and weaknesses, the advantages of open access to scientific information, the fundamental need to further value and qualify the work of editors and consultants. Particularly complex issues need to be included on the agenda, such as the need for funding to sustain the journals, which does not necessarily derive from submission and/or publication fees. And, above all, there is the urgent challenge to professionalize the editorial teams of Psychology journals.

This issue 56, volume 23 of Paidéia opens with the article entitled Relationships Between Positive and Negative Affect and the Five Factors of Personality in a Brazilian Sample, authored by Cristian Zanon, Micheline Roat Bastianello, Juliana Cerentini Pacico, and Claudio Simon Hutz of the Universidade Federal do Rio Grande do Sul, Brazil, which aimed to evaluate the occurrence of strong associations of Neuroticism and Extraversion with positive affects (PA) and negative affects (NA) in a Brazilian sample, and also to investigate the role of Conscientiousness, Agreeableness and Openness in the prediction of PA and NA through the use of a hybrid structural model. Participants were 319 university students and surprisingly, Agreeableness was shown to be a weak prediction for NA, but had no relationship with PA. As expected, Openness showed no relationship with PA or NA.

The article Validity Evidence for the Reduced Version of the Young Parenting Inventory (YPI), by Felipe Valentini, from Universidade de Federal do Paraná, João Carlos Alchieri, from Universidade Federal do Rio Grande do Norte, and Jacob Arie Laros, from Universidade de Brasília, Brazil, aimed to adapt a reduced version of the Young Parenting Inventory (YPI) to the Portuguese language and to obtain evidence of its validity. The instrument was administered to a sample of 920 persons (59\% female) and the exploratory factor analysis indicated the existence of five factors explaining approximately $45 \%$ of the variance. Confirmatory factor analysis showed fit indices above. 80 . In comparison with other models, the five factor model showed a better fit to the data.

The next article, Exploratory Study of the Diagnostic Abilities of the Baptista Depression Scale - Adult Version (EBADEP-A), by Makilim Nunes Baptista, Juliana Oliveira
Gomes, and Adriana Munhoz Carneiro of the Universidade São Francisco, Brazil, analyzed the diagnostic capabilities of a depression screening scale. The scale was administered along with the structured clinical interview from the DSM-IV (SCID-CV) and the Hamilton Depression Scale (HAM-D). Participants were 22 subjects diagnosed by psychiatrists with Major Depressive Disorder. The EBADEP-A correctly identified cases of depression, showing a high correlation with the HAM-D, which indicates that the scale correctly captures most depressive symptoms, even though it was initially used as a depression-screening tool.

The study Predictors of Sensitivity in Mothers of 8-Month-Old Infants, written by Patrícia Alvarenga and Maria Virginia Machado Dazzani, from Universidade Federal da Bahia, Cristiane Ajnamei dos Santos, from Universidade Federal do Recôncavo da Bahia, Alfaya Eulina da Rocha Lordelo, from Universidade Federal da Bahia, and Cesar Augusto Piccinini from Universidade Federal do Rio Grande do Sul, Brazil, investigated the impact of maternal mental health, including postpartum depression, and of maternal-fetal attachment on maternal sensitivity when babies were eight months old. The study included 38 mother-infant dyads. The multiple regression model considering the three factors explained $18.6 \%$ of the variance in sensitivity, and only maternal-fetal attachment was a significant predictor.

Subsequently, the article Achievement Goals of Youngsters in Rio de Janeiro in Different Contexts, authored by Dandara de Oliveira Ramos, Maria Lucia Seidl-de-Moura and Luciana Fontes Pessôa from Universidade do Estado do Rio de Janeiro, Brazil, compared the Future Goals of 160 university students and slum-dwelling youth (16-30 years-old; 71 female and 89 male). Favela youth showed higher levels of uncertainty while describing their goals and also presented lower scores of objectives. From an Evolutionary perspective of Psychology, through the Life Story Strategies Theory, it was concluded that, for young people from different social contexts, the ways of planning the future tend to vary depending on the adaptability of achievement due to the constraints present in the youth's realities.

The study Levels of Phonological Awareness, Working Memory, and Lexical Knowledge in Elementary School Children, by Heloisa Helena Motta Bandini, from Universidade Estadual de Ciências da Saúde de Alagoas, Flávia Heloísa Santos, from Universidade Estadual Paulista de Bauru, and Deisy das Graças de Souza, from Universidade Federal de São Carlos, Brazil, investigated the possible associations between specific phonological awareness abilities and phonological working memory in first-grade students. Students with low working memory and low phonological awareness capacities had low scores in expressive language abilities, suggesting that phonological working memory may have direct effects on lexical knowledge.

The article Personal Well-Being and Family Interactions of Working Couples With Preschool Children: A Correlational Study, authored by Danila Secolim Coser, Cláudia Maria 
Simões Martinez, and Renata Christian de Oliveira Pamplin, from Universidade Federal de São Carlos, Brazil, aimed to verify the existence of a relationship among variables declared by working mothers and fathers, related to personal well-being, parenting practices and interactions with their preschool children. The participants were 60 couples of workers from a countryside town in São Paulo state. Data were collected through the Questionnaire about familiar and professional life. Through statistical tests (One-Way ANOVA and Pearson's correlation coefficient) negative correlations between educational practices adopted and health problems reported by the parents were observed, as well as positive correlations between parental interactions and the educational practices declared.

The following article, Stimulus Equivalence and Increase of Correct Responses in Addition and Subtraction Problems, written by Marcelo Henrique Oliveira Henklain and João dos Santos Carmo, from Universidade Federal de São Carlos, Brazil, assessed whether the formation of two sets of addition and subtraction equivalence classes reaches the goal of increasing correct responses when solving arithmetic problems. This study also investigated the effect of training on balance type problem solving and the teaching of algorithms. Eight 2nd to 5th grade elementary school students served as participants. After the formation of classes, all participants showed an average growth of $25 \%$ in post-test 1 . Later, at the end of the training in balance type problem solving, there was an average growth of $25 \%$ in post-test 2 . In Generalization Test 1, all participants showed correct responses above $75 \%$. After the teaching of algorithms, there was an average growth of $8 \%$ in Post-test 3, and $100 \%$ correct answers in the reapplication of test generalization. The procedures employed produced gains in solving arithmetic problem behavior.

The study entitled Techniques Used in Forensic Psychological Examinations in Cases of Child and Adolescent Sexual Abuse, by Lara Lages Gava and Débora Dalbosco Dell'Aglio, from Universidade Federal do Rio Grande do Sul, Brazil, investigated the techniques used by forensic psychologists in practice in cases of suspected sexual abuse of children and adolescents in the context of criminal investigation. Semi-structured interviews were used with twelve psychologists who work as experts in the Medical-Legal Institute of six Brazilian capitals, which were qualitatively analyzed with the software WebQDA. Results showed a diversity of actions taken in forensic practice, as well as consensus and controversy regarding the use of psychological testing and credibility assessment.

The next article, Attachment and Parental Practices as Predictors of Behavioral Disorders in Boys and Girls, written by Sandra Adriana Neves Nunes, from Faculdade de Ilhéus, Ana Maria Xavier Faraco, and Mauro Luis Vieira, from Universidade Federal de Santa Catarina, Brazil, investigated how two parental systems (attachment and parental practices) interact to predict internalizing and externalizing behavioral problems in girls and boys. The Security Scale was administered to 289 children (mean age $=10.5$ years), and 205 parents completed the Child Behavior
Checklist, an instrument addressing parental practices. The results indicate that poor maternal attachment predicts aggression and delinquency in boys while problems of this nature among girls are predicted by parental rejection and low behavioral control.

Following the contributions, the article Marital Satisfaction: The Role of Social Skills of Husbands and Wives, by Miriam Bratfisch Villa and Zilda Aparecida Pereira Del Prette, from Universidade Federal de São Carlos, Brazil, investigated the correlations between marital satisfaction and the social skills of married couples. A total of 406 married individuals, 188 men and 218 women, completed the Marital Satisfaction Scale, Social Skills Inventory (SSI-Del-Prette) and Marital Social Skills Inventory (MSSI-Villa\&Del-Prette). The results revealed a significant correlation among the scores of the instruments, confirming the relationship between marital satisfaction and the social skills of married couples.

The article The First Experience of Clinical Practice on Psychology Students' Imaginary, authored by Sueli Regina Gallo-Belluzzo, Elisa Corbett, and Tânia Maria José Aiello-Vaisberg, from Pontifícia Universidade Católica de Campinas, Brazil, investigated the collective imaginary of Psychology students regarding the first clinical consultation. We conducted a group interview with 52 undergraduate students, using the Thematic Story-Drawing Procedure as a way to open a dialogical field. The material obtained, through the psychoanalytical method, resulted in the creation/gathering of four affective-emotional meaning fields: "I came, I saw and I conquered", "I know that I (do not) know", "I survived and I will save" and "I am and I do", from which we see an emotionally immature imaginary about the meeting with the patient, since students are more self-centered than concerned with the patient.

Concluding the issue, the review A Systematic Review of the Testing Effect in Learning, written by Raquel Eloísa Eisenkraemer, from Pontificia Universidade Católica do Rio Grande do Sul, Antônio Jaeger, from Universidade de São Paulo, and Lilian Milnitsky Stein, from Pontificia Universidade Católica do Rio Grande do Sul, Brazil, aimed to select and review articles on the testing effect to verify the extent and importance of this phenomenon, bringing the main results of recent research. To accomplish this, a systematic review of articles on this subject published between 2006 and 2012 was conducted, a period in which there was an acute increase in the amount of publications on this subject. The results, which were organized according to test format (recall and recognition tests), demonstrated that tests can be remarkably beneficial to the retention of long-term memories.

This issue closes with the list of the ad hoc Consultants who collaborated with Paidéia in 2013, followed by the Publication Standards. We hope the readers will have an enjoyable reading.

Manoel Antônio dos Santos Editor 


\section{References}

Marques, F. (2011). Os artigos quentes do Brasil: Estudo aponta os temas em que a ciência do país alcançou visibilidade internacional. Pesquisa FAPESP. Retrieved from http:// revistapesquisa.fapesp.br/2011/09/03/os-artigos-quentesdo-brasil/

Toledo, K. (2014). Especialistas defendem desenvolvimento de universidades de classe mundial. Pesquisa FAPESP. Retrieved from http://agencia.fapesp.br/18521

Zago, M. A. (2011). Evolução e perfil da produção científica brasileira. In: R. U. Sennes \& A. Britto Filho (Orgs.), Inovações tecnológicas no Brasil: Desempenho, políticas e potencial (pp. 41-54). São Paulo: Cultura Acadêmica.

How to cite this editorial:

Santos, M. A. (2013). Impact and visibility: What place does Psychology occupy in the Brazilian and international scientific production?. [Editorial]. Paidéia (Ribeirão Preto), 23(56), 281-284. doi:10.1590/1982-43272356201301. 